\title{
(META)LITERATURA Y UNIVERSOS PARALELOS EN EL MAPA DEL TIEMPO DE FÉLIX J. PALMA
}

\author{
José Antonio Calzón García \\ Universidad de Cantabria \\ joseantoniocalzon@gmail.com
}

\begin{abstract}
RESUMEN: El artículo, tras una breve introducción donde se repasan el origen, desarrollo, ideología y principales características del género steampunk, analiza la novela El mapa del tiempo de Félix J. Palma, a partir fundamentalmente de dos aspectos: las autorreferencias y los elementos metaliterarios, por un lado, y las alusiones temporales, por otro. La interconexión entre ambos aspectos permite concluir que en la novela el autor parece utilizar la idea de literatura en un sentido metafórico, con el que reflexionar sobre la doble consideración de la creación artistica como acto y potencia, en estrecha conexión con la idea de "universos paralelos", cuestionando asi el valor absoluto de la noción de tiempo.

PALABRAS CLAVE: steampunk, tiempo, metaliteratura, El mapa del tiempo, Félix J. Palma, retrofuturismo.
\end{abstract}

\section{(META)LITERATURE AND PARALLEL UNIVERSES IN EL MAPA DEL TIEMPO BY FÉLIX J. PALMA}

ABSTRACT: The article, after a brief introduction in which the origin, development, ideology and main features of steampunk genre are reviewed, analyses the novel El mapa del tiempo by Félix J. Palma, primarily from two pieces of information: self-references and metaliterary elements, on the one hand, and time allusions, on the other. The interconnection between both elements allows us to conclude that in this novel the author seems to use the idea of literature in a metaphorical sense, with which reflects upon the dual consideration of artistic creation like potency and act at the same time. This last point would be related to the idea of "parallel universes", which allows the possibility for contesting the absolute value of the idea of time.

KEYWORDS: steampunk, time, metaliterature, El mapa del tiempo, Félix J. Palma, retrofuturism.

Recibido: 11/04/2017. Aceptado: 06/11/2017 


\section{El steampunk. Definición, género y orígenes}

El reciente desarrollo, en los últimos años, del llamado género steampunk, dentro de la narrativa, ha llevado a diversas (re)formulaciones acerca de los aspectos definitorios de esta modalidad textual. Para Fernández (2011), el steampunk es "un subgénero de la literatura fantástica que huye del catastrofismo virtual [...] y aboga por un retrofuturismo salvaje que devuelve al mundo de la época victoriana y lo inunda de los avances técnicos [...] que aventuran las novelas de Julio Verne". De este modo, el género plantearía un universo paralelo desde la perspectiva del retrofuturismo, esto es, un "futuro anterior de una revolución industrial que nunca existió, donde lo fantástico se codea con el desarrollo de la tecnología y -sobre todo- de la ideología científica que lo acompaña" (Conte Imbert 2011: 268). Uno de sus principales autores en España, Félix J. Palma (2014), incide en destacar no solo la naturaleza aglutinadora del género, sino también la relevancia del uso del vapor en cuanto fuente de energía, a lo largo de estos relatos:

Se trata de un género cuyas historias suceden en una época alternativa presidida por la tecnología a vapor, generalmente localizadas en Inglaterra durante la época victoriana, y donde no es extraño encontrar elementos comunes de la ciencia ficción o la fantasía. La magia, el ocultismo y la brujería, por ejemplo, conviven en mayor o menor medida con la que quizás sea su característica más representativa: la presencia de la tecnología anacrónica, toda suerte de inventos y gadgets mecánicos que parecen sacados directamente de las ilustraciones futuristas del siglo XIX, aquellas que mostraban damas con corsés alados y carruajes aéreos.

De este modo, el steampunk se presentaría como una modalidad narrativa en la cual al aspecto poliédrico del género -sustentado sobre la ciencia-ficción, pero con características también de la novela fantástica- se sumaría no solo la ambientación frecuentemente victoriana, sino la relevancia del vapor en cuanto fuente de energía que pondría en marcha una miríada de dispositivos e incluso el juego ontológico que supone asumir el retrofuturismo en cuanto (re)lectura alternativa de un pasado reconstruido, en el cual ciertas tendencias tecnológicas habrían evolucionado de forma mucho más veloz de lo que realmente sucedió, mediante la configuración de una ucronía en la que el autor crea una hipótesis plausible, a partir de un incidente que haga derivar el curso de la historia (Matangrano 2016: 250). Y así, a caballo entre el pasado victoriano y el futuro contemplado desde la óptica punk, los steamers lanzan una mirada al pasado impregnado con percepciones del presente, y, simultáneamente, imaginan un 
futuro que podría realizarse, revistiendo de una nueva importancia el pasado del siglo XIX, mediante la inserción en él de valores y características tecnológicas contemporáneas (Maiolino Herschmann et al. 2013: 213-214, 226). En resumen, como ha explicado muy bien Pegoraro (2012b: 391), la literatura steampunk busca en el siglo XIX la visualización de un pasado reinventado en el presente.

A la hora de perfilar la adscripción genérica del steampunk, como ya hemos apuntado, nos enfrentamos al problema del eclecticismo:

La misma etiqueta steampunk plantea a mi juicio problemas de clasificación genérica, al englobar obras cuya lógica narrativa resulta muy dispar; si nos atenemos a las que se suelen enmarcar bajo su etiqueta, el steampunk acaba quebrando la frontera entre el universo mágico de la fantasy y la lógica causal de la ciencia ficción [...] Aquí, la lógica de lo fantástico se inmiscuye en un paradigma epistemológico propio de la ciencia ficción, lo cual responde, de alguna forma, a la disolución de categorías o fronteras a la que tiende un género como el steampunk. (Conte Imbert 2011: 264)

De igual modo, Matangrano (2016: 259-260) insiste en señalar cómo a lo largo del siglo XIX surgirá el debate entre tecnología/cientificismo frente a misticismo/fantasía, lo que llevará a que los géneros literarios se posicionen de un lado u otro. Así, mientras el realismo/naturalismo optará por posicionarse al lado del primer ámbito, el impresionismo/decadentismo/simbolismo se acercará al segundo. En medio de este antagonismo, y a pesar de la distancia temporal, el steampunk conciliaría ambas posturas, a partir del tratamiento más o menos fantástico del progreso científico, lo que da buena cuenta de la naturaleza sincrética de la narrativa retrofuturista.

Por otro lado, esta naturaleza integradora del steampunk se traduce de igual modo en una nutrida ramificación de subgéneros más o menos vinculados a la idea nuclear de este paradigma narrativo. Así, desde el clockpunk-centrado en el protagonismo de los autómatas- hasta el dieselpunk -más distópico y oscuro, con el gasóleo como referente energético-, pasando por el steampunk policíaco, el teslapunk -inspirado en la electricidad y en los inventos de Nikola Tesla-, la narración pseudogótica o la ucronía de ambientación más o menos decimonónica (Fernández 2011; Martín Rodríguez 2013; Fundación Teléfonica 2015; Matangrano 2016: 258), el steampunk parece ser, en ocasiones, un cajón de sastre al que incorporar cualquier relato de ambientación vintage en el que las tecnologías adquieren cierta relevancia narrativa. 
Pasando a la cuestión de sus orígenes, todo parece estar aparentemente más claro. Así, Fernández (2011), entre otros, insiste en apuntar el valor seminal de las narraciones de H. G. Wells y Julio Verne -a pesar de las notables diferencias ideológicas entre ambos, como ha notado Onion (2008: 140)-, al configurar un universo literario en el cual el siglo XIX se veía revestido, desde la especulación basada de forma laxa en los avances científicos, con los ornamentos de la protociencia-ficción. Sin embargo, las novelas fraguadas al calor de los scientific romances verían desdibujada su estela hasta que, mucho más tarde, ya en los años ochenta del siglo XX, autores anglosajones revitalizaran las narraciones científicas del siglo XIX, como testimonian sobre todo Tim Powers con The Anubis Gates (1983), James Blaylock con Homunculus (1986) y K. W. Jeter con Infernal Devices (1987), al retomar el molde genérico de la ambientación retro en clave fantástico-tecnológica. El steampunk, como consecuencia de ello, ha ido cobrando tal fuerza -tras Estados Unidos fundamentalmente en Alemania y Japón, en este último sobre todo en la cultura manga, como testimonian Steamboy o Casshern (Onion 2008: 14; Fernández 2011)- que incluso ha dado lugar a antologías, películas, series de cómics como The League of Extraordinary Gentlemen (Moore y O’Neil 1999-2012) o incluso publicaciones periódicas como el Steampunk Magazine, disponible en Internet ${ }^{1}$.

¿Qué ha llevado a la utilización del término steampunk para aludir a esta corriente retrofuturista ambientada en los relatos científicos del siglo XIX? Nada en las narraciones de Verne y Wells invita a pensar que tal término tuviera algún tipo de significado para un autor decimonónico. En realidad, será uno de los escritores que reformularán el género, $\mathrm{K}$. W. Jeter, quien acuñará el término en 1987, en respuesta a una reseña de Faren Miller en la que el propio autor se incluirá como uno de los cultivadores de la nueva tendencia, mientras cita de igual modo a los ya mencionados Tim Powers y James Blaylock: "Personally, I think Victorian fantasies are going to be the next big thing, as long as we can come up with a fitting collective for Powers, Blaylock and myself. Something based on the appropriate technology of that era, like 'steampunks', perhaps" (Usher 2011). Respecto al término, la partícula punk añadiría no solo la noción de "marginalidad" (Matangrano 2016: 247-248), sino la visión negativa del universo punk en relación con el desarrollo social y la degradación del individuo (Maiolino Herschmann et al. 2013: 216), lo que haría que, en última instancia, el término steampunk conjugue morfológicamente el elemento victoriano del vapor como fuente de energía con la perspectiva oscura y pesimista de la cultura punk.

1. Localizable en el sitio web http://www.steampunkmagazine.com/. 
En resumen, el steampunk, surgido fundamentalmente en el mundo anglosajón, parece consistir no solo en un (sub)género literario, sino en un espectro cultural sincrético desarrollado a partir del universo decimonónico de Julio Verne y H. G. Wells, al que se ha incorporado una revitalización de la imaginería tecnológica -sustentada sobre todo en el uso del vapor- desde el prisma que proporciona el escepticismo de los siglos XX y XXI en relación con el optimismo científico victoriano.

\section{Steampunk e ideología}

Tal y como apunta Fernández (2011), el steampunk parte de la premisa de que "la civilización no tomó el camino de la electrónica y los modernos combustibles sino el de la vieja tecnología del vapor [...] Un mundo avanzado hecho de la extraña [...] combinación de hierro, carbón y vapor", es decir, arranca desde un prisma retrofuturista en el que se concibe un universo paralelo que, irónicamente, "marca el nacimiento de la modernidad científica y tecnológica, en el ámbito de la posmodernidad, o sea al término de su ciclo" (Conte Imbert 2011: 268). De este modo, la relectura actual del universo decimonónico se hace desde el prisma de la desilusión ante la evolución del siglo XX, lo que lleva a contextualizar historias que suponen, al mismo tiempo, desarrollo tecnológico y degradación social, realizando así una crítica tanto al mundo de la racionalidad como del iluminismo (Maiolino Herschmann 2013: 216, 220). Así, el retrofuturismo permitirá explorar los límites y las tensiones entre la racionalidad y la alienación provenientes de los avances de la tecnología (Pegoraro 2012b: 393). Por otro lado, la importancia del universo victoriano se basa en que es la época de la revolución industrial y la eclosión de la ficción científica, lo que da pie a la promoción de preguntas en torno a la evolución de la tecnología, las interacciones hombre-máquina o los ideales de un pasado que prometía un mundo racionalizado, pero que no se cumplió (Pegoraro 2012a: 90, 102). De este modo, el mundo del XIX sirve como clave de análisis para la evolución de la sociedad actual: "steampunk's key lessons are not about the past. They are about the instability and obsolescence of our own times" (Sterling 2009: 30).

Un aspecto clave en la filosofía del steampunk es la denominada cultura del DIY, o "Do It Yourself". Así, los steamers parten de la idea de que el individuo ha de reapropiarse de una tecnología que, a lo largo del siglo XIX, fue alejándose progresivamente del individuo en cuanto agente con capacidad para la manufactura, quedando así en manos de la industria especializada: 
Steampunks see modern technology as offensively impermeable to the everyday person, and desire to return to an age when, they believe, machines were visible, human, fallible, and, above all, accesible [...] In the utopian steampunk world, knowledge about machinery would return to the hands of the people, subverting what steampunks see as an oppresive culture of specialisation. (Onion 2008: 145, 151)

En términos muy parecidos se manifiesta Pegoraro (2013: 1852), fundamentalmente a propósito del matiz marginal y contestatario que aporta la partícula punk:

Punk, for some authors of this style, evokes the idea of rebellion against the aesthetic of modern manufacturing, which is the critique of the aspect of massification/ industrialization of products. The steamers think these kind of products are made just to feed a circuit of consumption.

De este modo, la idea de la autosuficiencia se combina con la crítica al circuito mainstream, al racionalismo y al consumo exacerbado (Pegoraro 2012b: 399), convirtiendo a los steamers en modernos artesanos que contribuyen a divulgar los medios y métodos para trabajar las tecnologías arcaicas (Sterling 2009: 32). No en vano, la tecnología y el diseño, junto con la expresión textual, son fundamentales para la comunidad dedicada a la estética steampunk, definida en gran medida por actividades de (re)elaboración centradas en los objetos, partiendo de la premisa de que los steamers están menos interesados en recrear tecnologías específicas de este tiempo que en re-acceder a lo que ellos ven como el valor afectivo del mundo material del siglo XIX (Onion 2008: 138-139).

En resumen, y al margen de otras cuestiones ideológicas de no menor calado, como la subversión de los tradicionales roles jerárquicos hombre-mujer en la narrativa de algunas autoras -especialmente Gail Carriger y Cherie Priest (Fernández 2011) - o la reflexión crítica en torno al paisaje urbano, desde la noción de "ciudad oscura" (Conte Imbert 2011: 255), lo cierto es que el steampunk parece sobrepasar el mero cliché literario de dirigibles y máquinas de vapor para convertirse en un verdadero movimiento cultural que cuestiona el valor de la tecnología electrónica en la ultraespecializada sociedad industrial actual, la cual desconecta al individuo del proceso de fabricación, convirtiéndole en un mero consumidor. El steampunk parece recuperar el fetichismo por los objetos, y con ello el placer de la elaboración artesanal -no reñida con la utilización de dispositivos tecnológicos-, resignificando así el valor del sujeto dentro del circuito comercial. 


\section{El steampunk y España. Félix J. Palma}

Tal y como reconocía el autor en el que centraremos nuestra atención en las próximas páginas, "en España uno no podía ganarse la vida escribiendo obras fantásticas [...] creo que publicar una novela de ciencia ficción en España aún sigue siendo una gesta heroica" (Palma 2014). A la hora de encontrar explicación para tan devastador panorama, el propio Palma (2014) consideraba que "gran parte de la culpa se debe al monopolio que en nuestro país siempre ha ejercido el realismo". En una línea muy semejante, Martín Rodríguez (2013: 66) ha insistido en que "los escritores españoles han sido tradicionalmente muy reacios a la fantasía especulativa". El problema, para algunos, pudiera encontrarse en la propia recepción del género:

Con un pasado semejante, es normal que el lector español no esté educado en la fantasía. Quizás considere que leer sobre mundos que no existen es una pérdida de tiempo, que la fantasía no tiene nada que enseñarle, y muchos lectores creen que el esfuerzo de leer ha de recompensarse con la ampliación del conocimiento. (Palma 2014)

No obstante, y a pesar de la perspectiva desoladora, es posible rastrear, ya desde El Anacronópete (Gaspar y Rimbau 1887) -texto injustamente olvidado, a pesar de anticipar el tema del viaje en el tiempo, usando una máquina, antes que el mismísimo H. G. Wells, tal y como señala Ayala (1998)-, una línea narrativa en castellano que fusionaría ambiente decimonónico y especulación tecnológica, tal y como encontramos, por ejemplo, en Danza de tinieblas (2005), de Eduardo Vaquerizo, Lendaria, de Josué Ramos, El Dirigible, de Joseph Remesar o La Máquina del Juicio Final, de Raúl Montesdeoca, las tres últimas de un fructífero 2013. ${ }^{2}$ Sin embargo, el autor que ha logrado más éxito dentro del género steampunk en el ámbito hispano probablemente sea Félix J. Palma, en particular con la trilogía victoriana iniciada con la exitosa El mapa del tiempo (2008), galardonada con el XL Premio Ateneo de Sevilla, amén de su actividad como compilador en Steampunk: antología retrofuturista (2012) o de su inclusión en la primera antología de autores steampunk españoles traducidos el inglés, The Best of Spanish Steampunk (Womack 2015). A él, y en particular al análisis de

2. Dentro del ámbito hispano, Laraway (2013), por ejemplo, ha llamado la atención sobre una significativa serie de textos chilenos cercanos al steampunk. Así, entre estos tendríamos La segunda enciclopedia de Tlön (2007), de Sergio Meier; Synco (2008), de Jorge Baradit; 1899: Cuando los tiempos chocan (2011), de Francisco Ortega, o La sombra de fuego (2011), de Alberto Rojas. 
El mapa del tiempo (2008), están destinadas las próximas páginas. Así, en la novela de Palma nos encontraremos con un Londres victoriano en el que una serie de personajes reales o ficticios, fácilmente reconocibles por el lector en muchos casos - desde el escritor H. G. Wells a Jack el destripador-, ven sus vidas entrelazadas, siendo los asesinatos, las historias de amor y, sobre todo, los viajes en el tiempo -fraudulentos en unos casos, pero reales en otros- los mecanismos argumentales que hacen la historia avanzar, a partir de un relato donde el autor combina las peripecias con los juegos metaliterarios y con la reflexión en torno al valor absoluto de la idea de tiempo.

\section{El mapa del tiempo (I): construcciones narrativas y (meta)literarias}

Una de las características apuntadas con frecuencia por la crítica, a propósito de la narrativa steampunk, es la presencia frecuente en estos relatos de personajes históricos y literarios, como Julio Verne, H. G. Wells o Nikola Tesla, fruto en gran medida de la tendencia del género a "reciclar" hechos o personajes del pasado, sea este real o puramente ficcional (Matangrano 2016: 249, 252). No en vano, esta reutilización de figuras ya existentes consolida en cierto modo la propuesta del género de desarrollar universos paralelos a partir de material ya existente, como apunta Pegoraro (2013: 1853) a propósito de las premisas de los autores steampunk:

They reinvent established historical narratives by mixing in characters, facts and fiction. The idea is to re-elaborate situations that existed in the past by asking what would have happened if certain technical interventions had taken different directions, or by inserting present-day technology into the past environment.

Martín Rodríguez (2013: 70-71), dando un paso más, considera que uno de los propósitos principales de la ficción retrofuturista no es solo la reflexión en torno al devenir histórico, reformulado, sino indagar sobre la propia noción de la literatura:

La evolución de las sociedades humanas no es el objeto principal de un género cuya base no es la Historia, sino la propia literatura. La ficción retrofuturista es fundamentalmente metaliteraria, y de ahí la importancia señalada de los escritores del pasado y de su obra, porque se alimenta de fábulas, no de hechos acaecidos de verdad. La Historia deja de ser un proceso y se convierte en un telón de fondo. 
En efecto, una de las cuestiones que más llaman la atención en El mapa del tiempo es comprobar cómo la metaliteratura se va colando en la narración a través de las autorreferencias y de los guiños y saltos en los niveles narrativos, lo que lleva, en última instancia, a recodificar la obra, contemplándola en cuanto narración donde lo literario y el acto de escribir/narrar conllevan un valor metafórico que da pie a la reflexión en torno al sentido absoluto de la idea de tiempo, tal y como iremos viendo.

\subsection{El lector como (co)protagonista: leer y crear}

En El mapa del tiempo el autor implícito representado (Villanueva 1984) busca constantemente la implicación del lector a través de la "inmersión" de este en la propia narración, bien mediante el recurso del vocativo -"apreciado lector" (Palma 2009: 11, 267), " "gentiles caballeros y sensibles damas" (93)-, bien mediante su implicación actancial, a modo de espectador, usando una construcción retórica que involucra a su vez al autor-narrador: "darles la bienvenida a esta historia que acaba de empezar" (17); "al empezar la historia les he anunciado la aparición de una prodigiosa máquina" (71). En este juego, la segunda persona da pie, vicariamente, para que el relator juegue con la narración a su antojo: "permítanme ahora interrumpir la narración" (76); "permítanme ahora que realice un pequeño malabarismo narrativo" (122); "voy a aprovechar este claro en la acción para relatarles algo" (152); "voy a contarles, si me lo permiten" (296). Incluso, en ocasiones, la presencia del lector, y la aparente consideración hacia este por parte de la voz relatora, parecen condicionar un fragmento de la narración que en realidad está construido según la exclusiva voluntad del narrador: "por respeto a ustedes no incurriré en descripciones más minuciosas" (498). Por otro lado, dentro de este artefacto retórico, la voz narrativa juega también a anticiparse a las posibles reacciones del lector-espectador, controlando así, en cierto modo, un proceso interpretativo que involucra de igual modo al lector real: "como han podido deducir de algunas de mis intervenciones" (159); "como comprenderán, la mujer no necesitaba ninguna ayuda" (211); "ahórrenme afligirles con una lista de ejemplos" (260); "quizás les impaciente que vuelva a describírselo otra vez [...] deléitense en las trémulas sombras [...] jueguen a imaginar conejos" (396). De una u otra manera, lo cierto es que la voz relatora, a pesar de la importancia de lo libresco en la novela, insistirá en no pocas ocasiones

3. Todas las citas de El mapa del tiempo se realizarán a partir de la entrada incorporada en la bibliografía final. Ante los abundantes ejemplos, de ahora en adelante, y para facilitar la lectura, se indicará tan solo la página de la cita. 
en destacar la naturaleza oral de la narración, construyendo así una apariencia de interacción que refuerza indirectamente la implicación del lector en la historia: "diciéndoles" (160); "quizás hayan oído hablar" (307); "no les preguntaré" (396); "he evitado contarles" (442). Y así, el recurso de la oralidad y la configuración del lector en cuanto actante meramente retórico y pasivo pemitirán de igual modo dar punto y final a la historia narrada -"yo aprovecharé para despedirme de ustedes" (666)-, historia esta construida sobre la metáfora del juego de mesa en cuanto proceso de codificación-lectura: "permítanme que continúe disponiendo el tablero, sin prisa pero sin pausa" (71).

\subsection{La cuestión de la autorreferencialidad}

El narrador-autor, en El mapa del tiempo, configura un texto donde las referencias a la enunciación, y al responsable de esta, vuelven la narración, al margen del desarrollo de los acontecimientos, recursiva. Así, el propio narrador, en su diálogo constante con el narratario, aludirá una y otra vez a su actividad relatora, y a las dudas que esta le genera: "algunos de ustedes pensarán que he errado a la hora de escoger el hilo del cual empezar a tirar de la madeja" (17). Esta inseguridad se traduce en ocasiones en justificación, bien de ciertos pasajes de la novela con escaso peso narrativo -"narraré tal cual, pese a su escasa relevancia, simplemente porque no es mi intención dar un lustre extra a ninguno de los episodios" (222)-, bien de omisiones razonadas con argumentos de escasa fortaleza: "por respeto a ustedes no incurriré en descripciones más minuciosas" (498). En este sentido, las propias alusiones al proceso relator, en primera persona, son una constante en la que se incurre, probablemente, en exceso: "añadiré que pesaba poco más de cincuenta kilos" (160); "aquí podría terminar esta parte de la historia" (259); "y así voy a contarla" (296); "yo aprovecharé para despedirme" (666). A veces esta primera persona usa la forma plural, cual si de un maestro de ceremonias colectivo se tratara: "¿qué prodigios nos quedan aún por mostraros?" (493). Por último, en el cierre de la historia, el narrador -heterodiegético, no lo olvidemos- juega con la idea de que los personajes puedan sentir su "presencia", de una u otra manera: "se dijo que aquella imagen era perfecta para poner el punto final a la historia, y se preguntó, como si de algún modo pudiera verme o sentirme, si realmente habría alguien haciéndolo en aquel instante" (668).

Por otro lado, el texto se construye desde una fórmula metanarrativa en la cual el propio mensaje cae en los excesos de la autorreferencia: "sumérgete en las 
apasionantes páginas de nuestro folletín" (11); “en las próximas páginas de este emocionante folletín" (267); "volverá a aparecer en algún recodo de esta historia" (28); "continuemos con nuestra narración" (33); "las páginas finales de nuestro apasionante folletín" (493), etc. Estas autorreferencias se mezclarán, como ya se ha apuntado, con las vacilaciones en torno al proceso de elaboración escrituraria -"para contar solo la historia de Andrew mi intervención no sería necesaria: podría contarla él mismo" (259)-, vacilaciones que en ocasiones alternarán con la legitimación del relator y de su criterio a la hora de narrar: "de la paja he de sacar el grano" (260). Asimismo, como sucediera con el narrador, las autorreferencias de la novela servirán también como mecanismo retórico con el que cerrar la obra: "ya se presiente el final de esta historia" (666).

\subsection{El relator todopoderoso}

A lo largo del libro, Félix J. Palma construye una historia en la cual el narrador asume un papel ambiguo y bivalente, fruto de la articulación entre la construcción de un rol sólido - consecuencia de la omnisciencia y del control explícito sobre lo narrado- y la retórica asunción de que, por momentos, el relato parece escapar a la tutela de su agente enunciador, sobrepasado este por la dificultad que supone enfrentarse al hecho de contar.

Respecto a la primera de las posturas, esto es, la del narrador seguro y confiado, la omnisciencia se deja entrever con absoluta transparencia en no pocos ejemplos. Así, el relator se ve como el único conocedor de los misterios de la trama -"algo que quedó pendiente en los comienzos de esta historia, y que solo yo puedo contarles" (152)-, a quien nada se la escapa -"yo, que todo lo veo" (647)-, incluso en contra de su voluntad: "yo, en cambio, todo lo veo y todo lo oigo aunque no quiera" (260); "y yo, que todo lo veo aunque no tenga el menor interés en ello" (497). De igual modo, la voz relatora asume de forma clara, sin ambages, el control de la narración, bien recurriendo de nuevo a la metáfora del juego -"¿acaso no es necesario, antes de empezar cualquier partida, colocar las piezas en sus correspondientes escaques? Ciertamente, así que permítanme que continúe disponiendo el tablero" (71)- o de la maniobra circense -"permítanme ahora que realice un pequeño malabarismo narrativo" (122)-, bien explicitando su poder decisorio sobre la materia novelable, o sobre la forma de esta: "y con eso veo innecesario añadir nada más" (153); "cuya crónica [...] he juzgado apropiada para amenizarles el fatigoso viaje" (159); "narraré tal cual, pese a su escasa relevancia, simplemente porque no es mi intención dar un lustre extra a ninguno 
de los episodios de este relato" (222); "a partir de ahora llamaré por su verdadero nombre, Tom Blunt" (346). En ocasiones, el control sobre la narración, y el escamoteo de información, quedan diluidos retóricamente en aras de una moral absolutamente postiza: "quizás les impaciente que vuelva a describírselo otra vez, pero me temo que es lo que haré, pues no tengo ninguna intención de traspasar la puerta de la habitación donde se hallan Tom y Claire con el indecoroso propósito de invadir su intimidad" (396); "comenzó a relatarle [...] lo que, por otro lado, yo tanto he evitado contarles para proteger su intimidad" (442).

Otro elemento que determina el rol del narrador a la hora de evidenciar su control sobre la narración es el recurso de la deixis y la anticipación. Así, en primer lugar, el narrador juega con los elementos fóricos en no pocas ocasiones para remitir anafóricamente a acontecimientos ya narrados: "las mezquindades más notables, como ya se ha visto" (152); "será inevitable retroceder unos instantes hasta el momento en que Charles repara en el olvido del sombrero" (260); "no alarmaron al hombre, como ya hemos dicho" (297), etc. De igual modo, la prolepsis y la deixis catafórica sugerirán al lector en no pocas ocasiones líneas narrativas anticipadas por el relator: "capaz de las hazañas más extraordinarias en el campo de batalla de los negocios, como a continuación se verá" (152); "enseguida descubro que el instante escogido para irrumpir en la vida del escritor Herbert George Wells no es un buen momento" (160); "apreciado lector [...] tendrás el privilegio de viajar al futuro para conocer la célebre guerra del año 2000 contra los malvados autómatas" (267); "ignoraba, naturalmente, que veinte días después se encontraría tumbado sobre ella con su boca a un beso de distancia de la suya" (287-288); "comenzó a contar cómo los autómatas se habían apoderado del planeta, una historia que [...] así voy a contar, si me lo permiten" (296); "se perdió entre los cascotes decidido a cumplir su destino, que no era otro que convertirse en el [...] hombre que acabaría con el rey de los autómatas" (309); "si queréis averiguarlo [...] aquí podréis viajar a voluntad en el tiempo, tanto al pasado como al futuro" (493); "ya se presiente el final de esta historia" (666), etc. De este modo, el narrador no solo juega con la historia, sino también con el propio discurso, recurriendo de nuevo a la metanarración para explicitar su control constante sobre enunciación y enunciado.

\subsection{El relator inseguro}

Paradójicamente, y de forma muy marginal, la figura del narrador juega también, asumiendo el rol de la ambivalencia, a mostrar ante el lector cierta imagen 
que mina su omnipotencia. Así, por ejemplo, en ocasiones, la voz relatora, desde el plano puramente retórico, muestra cierta incapacidad para controlar la narración: "dejemos por tanto a Harold, del que ni siquiera me atrevo a decir si volverá a aparecer en algún recodo de esta historia, porque muchos son los personajes que por ella transitarán y uno no puede quedarse con todas las caras" (28); "pero no nos dejemos arrastrar por el dramatismo y continuemos con nuestra narración" (33). De igual modo, el desafío ante la actividad enunciadora se revela en ocasiones al agente relator como una ardua empresa: "permítanme ahora interrumpir la narración para advertirles de que lo que ocurrió a continuación es difícil de relatar [...] les rogaría que no achaquen a mi torpeza narrativa las discrepancias que sin duda apreciarán entre los sucesos y su correlación en el tiempo" (76). En cualquier caso, y a pesar de estos guiños, lo cierto es que la construcción del narrador en cuanto voz omnipotente sobrepasa con mucho a las esporádicas alusiones en torno a sus flaquezas.

\subsection{Metalepsis y saltos narrativos}

Formulada por Genette (2004: 137) en cuanto proceso en el cual el pasaje de un mundo narrativo o enunciativo a otro se encuentra enmascarado o subvertido de alguna forma, la metalepsis representa, en última instancia, una formulación autorreferencial de "cualquier enunciado acerca de sí mismo" (Genette 2004: 129), en la cual la casuística puede ser amplísima. Así, en el caso de El mapa del tiempo, el salto narrativo más frecuente es la construcción del narrador externo heterodiegético en cuanto personaje que participa de una u otra forma en la historia, bien como espectador real de los acontecimientos - "en un abrir y cerrar de ojos [...] nos encontramos flotando sobre el tejado de una modesta casa" (159); "no tengo ninguna intención de traspasar la puerta de la habitación donde se hallan Tom y Claire" (396); "se preguntó, como si de algún modo pudiera verme o sentirme" (668)-, bien como partícipe en la interacción con los personajes: "en la vida del escritor Herbert George Wells [...] para no incordiarle demasiado, podría despachar su descripción física" (160). Otras veces, el narrador no salta hacia el plano metadiegético, sino hacia el extraliterario, fundamentalmente de la mano del lector, para jugar la baza de la retitentia: "ahórrenme afligirles con una lista de ejemplos que pueden encontrar [...] en sus propias vidas" (260); "aunque por respeto a ustedes no incurriré en descripciones más minuciosas" (498).

Por otro lado, no es menos frecuente, por parte del narrador, el recurso de inmiscuir al lector en la historia, "sumergiéndole" en el universo metadiegético 
mediante la ilusión de su participación como personaje en esta: “imagino que a ustedes, que de algún modo también viajan en el carruaje, sí puede resultarles algo incómodo" (151); "cuya crónica [...] he juzgado apropiada para amenizarles el fatigoso viaje" (159); "regresemos ahora con Wells" (666). Otras veces, el lector real es interpelado a fin de hacerle creer su presunta condición de copartícipe en la narración, aunque solo sea a partir de fórmulas puramente retóricas: "una historia que [...] podría haber constituido perfectamente el argumento de alguna de esas novelas [...] y así voy a contarla, si me lo permiten" (296). En este mismo sentido, el narrador parece anticiparse a nuestras propias reacciones ante el relato, situándonos así en el nivel diegético de la historia: "quizás les impaciente que vuelva a describírselo otra vez" (396).

Al margen de los dos "desplazamientos" citados -el del narrador y el del lector-, en la obra se juega también con la metalepsis desde otros prismas. Así, cuando la novela está a punto de concluir, el narrador hace coincidir la finalización de esta con las cábalas del H. G. Wells personaje en torno al punto y final en un hipotético relato de su vida: "aunque si alguien [...] había emprendido la escritura de su vida, fuera en la época que fuese, esperaba por su bien que ahora se encontrase en la última página" (667). De igual modo, resulta especialmente interesante el pasaje en el cual uno de los personajes hace suyas unas palabras que previamente, páginas atrás, ha usado el verdadero narrador heterodiegético para describir al mismo individuo: "un majestuoso espécimen de la raza humana, adornado con una musculatura imponente y un rostro airoso, de cuyos ojos rebosaba la ferocidad de una pantera acorralada" $(414,418)$. Por último, y a pesar de no tratarse, sensu stricto, de una metalepsis, en el momento en el que el H. G. Wells del futuro escribe una carta a su yo del presente -según el tiempo de la historia-, la alternancia entre la primera y la segunda persona cuestionará de igual modo la solidez de los roles de emisor y destinatario: "ahora, si me permites, continuaré narrando lo sucedido en primera persona. Al principio, no entendí lo que había pasado [...] es algo que dejo a tu elección, yo no soy quien para entrometerme en tu matrimonio" $(617,625)$.

\subsection{Textos y más textos}

Si bien el steampunk es un género en el cual es moneda de uso corriente recurrir a figuras literarias tanto reales como fantásticas -esto es, utilizar como personajes a escritores o a creaciones de sus obras-, en el caso de El mapa del tiempo este recurso metaliterario adquiere una especial intensidad, bien para aludir a textos preexistentes, bien para construir estructuras recursivas de textos dentro de 
textos. En este sentido, el género más frecuente en la obra será, sin duda, el epistolar: "se encontró con la reproducción de una carta que el asesino había tenido la osadía de enviar" (66); "sacó la carta y se la entregó a Wells" (420). No obstante, encontraremos igualmente textos publicitarios - “Está cansado de viajar en el espacio? Ahora puede viajar en la cuarta dimensión, a través del tiempo" (93)- u otros literarios -si bien pertenecientes en exclusiva al universo ficcional construido en la novela-, que serán mencionados de forma indirecta a través de valoraciones críticas o analíticas: "naturalmente me esforcé en que estuviese bien escrita, pero lo que más me interesaba era su propuesta profética" (533). Por otro lado, las alusiones a conocidas, y verdaderas, obras de la literatura, especialmente la anglosajona, salpicarán el relato una y otra vez: "un caso verdaderamente interesante, más propio de una novela de su admirado Sherlock Holmes" (497); "del tipo de las que pergeñaba su colega Doyle" (555). En este sentido, cobrarán un especial protagonismo las obras, reales o hipotéticas, del escritor H. G. Wells, convertido a su vez en uno de los protagonistas del relato: "pero su novela, señor Wells... ¡su novela me fascinó como ninguna lo había hecho antes! Usted no habla del mundo que conocía, como hacía Dickens" (531); "si él [Wells] hubiese tenido algún interés por escribir una novela policíaca [...] jamás habría descrito a su detective como el jovencito que tenía delante" (555); "siempre le inundaba una poderosa quietud cuando ponía el punto final a una novela, como acababa de hacer con El hombre invisible" (650). No obstante, y como se verá en el siguiente apartado, una parte significativa de estas referencias metatextuales guardarán estrecha conexión con uno de los temas nucleares en la obra, esto es, la reflexión en torno a la noción de tiempo.

En conclusión, uno de los objetivos fundamentales en El mapa del tiempo es explicitar la condición de artefacto literario del relato, a través de mecanismos que ponen ante los ojos del espectador no solo a las distintas instancias imbricadas en los diferentes niveles narrativos, sino su condición de piezas postizas, creadas a voluntad del autor. En este sentido, las autorreferencias -tanto por parte de los agentes enunciadores como desde la propia narración-, las recursividades narrativas y las alusiones metaliterarias coadyuvan a desarrollar en la mente del lector una mayor preocupación por la forma y la estructura que por el propio fondo del relato, haciendo de este un laberinto de voces y textos interconectados.

\section{El mapa del tiempo (ii): tiempo y literatura a través del juego narrativo}

Como se ha apuntado, uno de los elementos nucleares en la literatura steampunk es el retrofuturismo, según el cual la idea sería revivir o reelaborar situaciones 
que existieron en el pasado, cuestionando, por ejemplo, lo que habría sucedido en el caso de que algunas invenciones técnicas hubieran tomado rumbos diferentes y/o introduciendo la tecnología de nuestro tiempo en ese ambiente del pasado, con el objetivo de promover una transgresión negociada entre pasado, presente y futuro (Pegoraro 2012b: 393, 395). La ironía, por tanto, radica en que el género ofrece una mirada hacia el pasado impregnado de percepciones del presente, al tiempo que imagina un futuro que no ocurrió para ese pasado. De este modo, los participantes en el universo steampunk proyectan cambios de valores, de destinos y de la propia Historia, al menos en ese mundo alternativo (Pegoraro 2012a: 87, 104). Este proceso de resignificación del pasado es, en suma, una de las claves del género: "as Czeslaw Milosz wisely said, the past takes its meaning from whatever we do right now [...] The past is a kind of future that has already happened" (Sterling 2009: 33).

Uno de los aspectos filosóficos más sugerentes surgidos de la narrativa retrofuturista es el desarrollo de la noción de "universo paralelo", cuestión esta que lleva a un replanteamiento de la noción del tiempo en cuanto valor absoluto, siempre en conexión con la realidad inmediata del lector:

El steampunk [...] sería [...] una rama de la ucronía, caracterizada por el desarrollo de la tecnología y de la cosmovisión victorianas en una línea histórica paralela a la real hacia un "futuro alternativo" al nuestro [...] El escritor retrofuturista recrea no sólo un presente y un futuro imaginados como lo podrían haber hecho aquellos pioneros de la anticipación, sino también el mismo pasado, en el cual se hacen realidad, en el territorio de la ficción, los temores y las expectativas de entonces [...] El efecto especulativo de la ucronía depende de la existencia de un paralelismo virtual entre ambos transcursos históricos [...] En la historia alternativa, siempre existe una relación dialéctica implícita o expresa con el presente. (Martín Rodríguez 2013: 66, 70)

En suma, tanto si entendemos el steampunk desde la perspectiva de los "futuros caducados", al hilo de la Revolución industrial (Fundación Telefónica 2015), como si lo contemplamos desde el juego especulativo del “ ¿y si...?”, mezclando fantasía y realidad, hechos históricos y personajes ficticios (García Costa 2013: 16), lo cierto es que uno de los elementos más seductores del género es precisamente su potencial como molde genérico con el que especular y teorizar acerca de la idea de tiempo y la posibilidad de los universos paralelos. En este sentido, El mapa del tiempo ofrecerá todo un inventario de guiños y referencias temporales con los que viajar a través de las instancias narrativas y los juegos metaliterarios, para llegar en última instancia a la formulación de la pregunta crucial: ¿qué significa ahora? 


\subsection{Tiempo y enunciación: a vueltas con los niveles narrativos}

La especial preeminencia que el aspecto temporal tiene en El mapa del tiempo comienza a cobrar protagonismo a partir de la tríada tiempo-narraciónlector. Así, el narrador buscará la complicidad del lector -sumergido este en la historia desde la metáfora del viaje: "te aseguramos que este último viaje merece la pena" (493)-, respecto a la historia, desde una concepción laxa del elemento temporal: "si como cualquier persona cabal crees que el tiempo es una corriente que arrastra rápidamente todo lo que nace [...] aquí descubrirás que el pasado puede hollarse de nuevo" (11); "necesito que consideren la flexibilidad del tiempo, su capacidad para estirarse o encogerse como un acordeón a espaldas de los relojes" (76). En este sentido, hacia el final de la obra irrumpirá en el relato un nuevo personaje, una especie de bibliotecario que posee la capacidad de viajar en el tiempo, lo que supone la traslación del esquema ternario citado al plano metadiegético:

Llamamos Biblioteca de la Verdad al lugar donde se conserva la memoria del mundo, y yo soy uno de los bibliotecarios, al que corresponde velar el siglo XIX. Para ello, me desplazo desde el Oligoceno hasta aquí, y mediante pequeños saltos entre décadas, compruebo que todo esté en orden. (585)

De igual modo, los personajes se verán también a veces reconvertidos en eventuales lectores, en ocasiones de sus propios textos, lo que llevará a más de una paradójica situación con la idea de los viajes temporales, cuando un yo futuro escriba a su yo presente, según el momento de la historia, tal y como le sucederá al mismísimo H. G. Wells: "Querido Bertie: Si tienes esta carta en tus manos es que estoy en lo cierto y en el futuro se podrá viajar en el tiempo [...] esta carta [...] llevará tu sangre y la mía, pues como habrás deducido por la letra, yo soy tú. Un Wells del futuro. Un futuro muy lejano" (610). Precisamente, la figura del Wells escritor, en calidad de autor-lector, sirve para configurar toda una reflexión sobre la idea de literatura como potencia y como acto, conectando así esta dicotomía con la noción de universo paralelo:4 "en aquel momento [...] podía escribir cualquier cosa, y eso le inoculaba [...] una libertad feroz, pero tan hermosa como fugaz, pues era consciente de que desaparecería en el instante en que escogiese una historia e inevitablemente perdiera todas las demás" (650). Wells volverá una y otra vez, en sus cavilaciones, a esta idea, lo que sin duda constituye uno de los

4. Respecto a la importancia de H. G. Wells en las referencias a los posibles universos paralelos en la novela, véase Hesles Sánchez (2013: 692-694). 
pilares filosóficos de la novela: “¿qué ocurría con los universos no elegidos, con esos mundos que se iban por el desagüe, por qué tenían menos derecho a existir que los otros? [...] Era más lógico pensar que cuando el hombre se enfrentaba a dos o más opciones, terminaba eligiéndolas [...] todas" (663-664). Incluso, en un guiño al género steampunk, el propio escritor fantaseará, no solo con la posibilidad de ser personaje de narraciones ajenas - ¿ ¿y si su vida estaba siendo escrita por alguien de otra realidad, por ejemplo de ese universo paralelo tan parecido al suyo?" (666)-, sino con la idea del relato retrofuturista: "¿significaba eso que no podía escribirse una novela centrada en su época en la que se especulara con un futuro que ya era pasado para su autor? Era triste pensar eso" (667).

Por otro lado, los distintos niveles enunciativos, y la esporádica naturaleza metanarrativa de la novela, llevan a insertar dentro de la historia subtextos, o alusiones intertextuales a estos, conectados de una u otra forma con la idea de tiempo. Así, de todos ellos, sin duda el más significativo será el "mapa del tiempo" (591), que da nombre a la novela, pero no será ni mucho menos el único. La lista de ejemplos es amplísima, centrada con frecuencia en las obras de Wells alusivas a temáticas temporales: "publicó un cuento por entregas titulado Los argonautas del tiempo" (150); "sirviéndose para ello de una teoría que ya había desarrollado en anteriores ensayos en el Fortnightly Review: el tratamiento del tiempo como la cuarta dimensión" (206); "la historia del viajero en el tiempo constaría de dos partes" (208); "como La máquina del tiempo, se trataba también de un romance científico" (417); "unos años antes, él mismo había escrito en el Pall Mall Dubget un artículo en el que preveía el aspecto que el hombre iría adquiriendo con el discurrir de los siglos" (573). No obstante, también se aludirá a textos de temática temporal de otros autores: "el mismísimo Verne había escrito una novela titulada París en el siglo $X X$, en la que se mostraba el mundo del mañana" (209-210); "se había leído por encima El libro de los espíritus de Allan Kardec, lo que le permitía interrogar a los muertos" (273); "como las del neoyorkino Luis Senarens, pobladas de aeronaves en las que sus protagonistas exploraban los territorios más salvajes del planeta" (425). Incluso, la irrupción de Bram Stoker (596) y Henry James (598), en compañía de Wells, servirá también para desarrollar un nuevo juego narrativo, a partir de la idea de que un viajero del tiempo les habría arrebatado sus manuscritos antes de ser publicados: "era evidente que nadie podía conocer el comienzo de su novela, salvo un hombre que proviniese del futuro" (560); "el año próximo un escritor desconocido llamado Melvin Frost publicará tres novelas que lo convertirán de la noche a la mañana en una celebridad y le harán pasar a la historia de la literatura" (596). De igual modo, las referencias textuales de índole temporal figurarán también en los recortes periodísticos 
-"tomó el recorte [...] una vez lo hizo, se encontró con el mismo titular que llevaba años leyendo [...] su contenido era también idéntico" (249); "el titular hablaba sobre el imparable avance del ejército de autómatas" (139)-, en los folletos publicitarios -"en el papelito, la empresa Viajes Temporales Murray anunciaba viajes en el tiempo" (274); "recibo un folleto como este [...] usted es el salvador de la raza humana, el hombre que en el año 2000 liberará nuestro planeta del yugo de los malvados autómatas" (415)-, en los mapas -"se trataba de un mapa del año 1666 [...] el mapa no mostraba el menor efecto de haber tenido que atravesar más de dos siglos" (565-566) - o en las prácticas quirománticas: “jamás había consentido que le leyera la mano [...] descubrir qué le tenía reservado el destino acabaría matando su curiosidad" (354); "siguió las líneas de su palma [...] jaquí está escrita... tu muerte!" (373). En este sentido, uno de los elementos nucleares de la trama es el cruce de misivas entre el capitán Shackleton -un pretendido viajero en el tiempo que no es más que el secuaz de un embaucador- y la joven, enamoradiza e ingenua Claire, sustentado en una supuesta reciprocidad epistolar a través del tiempo basada en un fraude y en la que, irónicamente, será la pluma de Wells la que asuma la voz del capitán: "me he enamorado de ti por tus cartas [...] las cartas de amor que nos hemos enviado todos estos años" (385); "te escribí una carta contestando a la tuya, y en mi siguiente viaje al siglo XIX [...] la dejé junto a la misma lápida" (387); “cómo puedo enamorarme de usted [...] si ni siquiera la he visto?" (439); "te contaré cómo sucederá todo" (442); "¿qué puedo decirte salvo que te amo y que te amaré tal y como dices?" (452). El propio Wells, como ya se ha mencionado, será a su vez también destinador y destinatario de otra carta remitida a sí mismo desde el futuro: "el escritor observó que se trataba de una carta. Un tanto confundido, la tomó de aquella mano de nieve. Para H. G. Wells. Entregar la noche del 26 de noviembre de 1896, leyó en el dorso" (609).

En resumidas cuentas, en El mapa del tiempo Félix J. Palma recurre una y otra vez a la metaliteratura, a las recursividades enunciativas y a los saltos entre los niveles narrativos, para poner sobre la mesa la cuestionabilidad de la noción de tiempo en relación con la idea de la creación artística, desarrollando así la sugerente reflexión de que el concepto de "universo paralelo" del género steampunk no hace más que plantear en clave metafórica el dilema de todo artista a la hora de escoger entre la obra realizada y otros caminos creativos no desarrollados. Esto conducirá en última instancia, como se verá a continuación, a un relativismo ontológico que ponga en duda la concepción del tiempo en cuanto valor absoluto. 


\subsection{Tiempo y literatura: todo es cuestión de perspectivas}

En la novela de Palma la idea de tiempo se irá viendo progresivamente cuestionada, a medida que el propio narrador haga avanzar la historia. Así, y al margen de que la percepción subjetiva de la linealidad cronológica, y de su duración, aparezca en más de una ocasión, a propósito de los personajes -"lo que Andrew experimentó en esos instantes brevísimos durante los que permaneció ante el cuerpo de Marie Kelly, aunque así descrito parezca que estuvo horas contemplándola" (79)-, la consideración einsteniana del tiempo en cuanto cuarta dimensión (206), por la que uno puede moverse igual que por el espacio, llevará al narrador a plantear la idea de los universos paralelos, sembrando con ella la duda acerca del verdadero sentido de nuestra propia temporalidad: "cada uno de los otros cordeles representa un mundo paralelo" (594); "es como si su acto hubiese producido una bifurcación en el tiempo, como si se hubiese creado una especie de universo alternativo, un mundo paralelo" (251); "siempre podía consolarse pensando que afortunadamente tenía una vida plena en otro sitio, lejano y próximo a un tiempo: un lugar inaccesible que no figuraba en ningún mapa, pues se hallaba en su envés" (256). Incluso, los universos paralelos servirán para dar legitimidad teórica a la obra, ante los problemas de verosimilitud que pudiera plantear uno de los principales recursos de la novela, esto es, los viajes en el tiempo: "se supone que los universos paralelos son una vía para evitar las paradojas temporales que podrían producirse en el caso de que el pasado no fuese algo blindado [...] ¿Qué pasaría [...] si alguien viaja en el tiempo y mata a su propia abuela antes de que dé a luz a su madre?" (588).

Por otra parte, una vez asumido el valor relativo del tiempo en la novela, el narrador se permite no pocos juegos, o guiños, con los que divertir al lector a partir de las situaciones construidas en el relato. Así, por ejemplo, cuando Wells, en nombre del capitán Shackleton, escriba a Claire -supuestamente desde el futuro, aunque sabemos que es un fraude-, aludirá a una situación en apariencia surgida de la fantasía, pero absolutamente factible en realidad, pues el lector sabe que Wells, Shackleton y Claire están compartiendo época y ciudad: “Amor mío: En mi mundo no existen los narcisos, ni queda el menor rastro de ninguna otra flor, pero te aseguro que al leer tu carta casi puedo olerlas. Sí, puedo verme a tu lado, en el jardín del que me hablas [...] De algún modo, amor mío [...] puedo olerlos desde aqui" (459). De igual modo, asistiremos a un guiño metaliterario cuando Wells, tras todos los acontecimientos ocurridos, se pregunte si "había en todo aquello material para una novela" (666), pensamiento este que en realidad hemos de poner en relación con la propia gestación de El mapa del tiempo. Idéntico 
juego encontraremos unas líneas más adelante, de nuevo de la mano de Wells, cuando aluda a un posible final para su biografía que, en realidad, está coincidiendo con el verdadero término de la novela que tenemos entre nuestras manos: "aunque si alguien, en un universo vecino, había emprendido la escritura de su vida, fuera en la época que fuese, esperaba por su bien que ahora se encontrase en la última página" (p. 667).

Siguiendo en esta misma línea, la obra dará pie a un sinfín de confusiones e incongruencias a partir de los viajes temporales -reales y falsos, según la situación- que en ella se plantean. Así, ya los propios personajes se preguntarán por las situaciones paradójicas que los desplazamientos temporales puedan generar: "si hemos aparecido en el futuro justo antes de la batalla que decidirá el destino del planeta, igual que la primera expedición, ¿no deberíamos encontrarnos aquí con ellos?" (321); "entiendo que te sorprenda, pero imagíname a mí. Yo leía la carta en la que hablabas de cómo nos habíamos amado lleno de asombro, pues era algo que desde tu punto de vista ya habíamos hecho, pero que todavía no había sucedido para mí" (388); “¿cómo puedo enamorarme de usted, señorita Haggerty, si ni siquiera la he visto?" (439). No obstante, la asunción de la complejidad ontológica de los viajes en el tiempo hará que los personajes -crédulos unas veces, y embaucando otras- terminen aceptando, con mayor o menor grado de comprensión, situaciones que parecen rayar en la inverosimilitud: "solo puedo decirte que te amo, Claire Haggerty, seas quien seas. Te amo desde este mismo momento y para siempre" (440); "dentro de unos meses, nuestra historia comenzará para ti. Para mí, sin embargo, acaba ahora, al poner el punto y final a esta carta" (465); "el día en que la mujer dio a luz, el muchacho supo que no vería crecer a su hijo, que por otro lado había venido al mundo con la misión de fecundar a su propia madre" (471); "si se escondía para aguardar el regreso de la segunda expedición, tendría que verse a sí mismo" (517); "muchos físicos sostenían que si viajábamos al pasado, por ejemplo, con el propósito de matar a alguien, la pistola nos estallaría en las manos debido a que el universo se autorregeneraría" (581). En cualquier caso, la perplejidad sacudirá a los personajes en más de una ocasión: “¿quiere decir que si viaja al año 2000 y detiene al asesino el crimen se... borrará?" (505). Y, de nuevo, H. G. Wells será uno de los protagonistas que con mayor grado de tolerancia habrá de enfrentarse a los retos de las paradojas temporales: "estábamos pintando las paredes del salón, cuando un niño de unos tres o cuatro años se materializó de repente [...] y volvió a desaparecer [...] comprendimos entonces que en nosotros empezaba el futuro" (635); "pero Wells no pudo oírlo porque en ese preciso momento, aquel universo desapareció como si nunca hubiese existido" (648); "con un número casi infinito de mundos 
diferentes, reflexionó Wells, todo lo que era susceptible de suceder, sucedía. O lo que era lo mismo: cualquier mundo, civilización, criatura o situación que pudiera imaginarse, existiría ya" (665).

En resumen, la novela de Félix J. Palma constituye un relato en el cual la idea de tiempo se convierte no solo en un elemento fundamental para hacer avanzar la historia, sino en un tema filosófico a partir del cual divagar acerca del valor absoluto de nuestras concepciones en torno al devenir cronológico. Así, tanto las reflexiones relativistas de narrador y personajes como los juegos y guiños alrededor de la idea de tiempo, amén de las diversas incongruencias en las que los propios personajes reparan, sirven para otorgar a los viajes en el tiempo un valor no solo narrativo, sino filosófico, en El mapa del tiempo.

\section{Conclusiones}

El género steampunk parece venir lastrado de base fundamentalmente por dos motivos: su pertenencia a un ámbito narrativo -la ciencia-ficción- denostado por la crítica y tradicionalmente ninguneado por los lectores del ámbito hispano, y su apuesta por una variante de la narrativa especulativa -el relato retrofuturista- que le hace perder, en teoría, todo poder predictivo. A pesar de ello, tanto autores como críticos han insistido en apuntar que la corriente steampunk ha servido para plantear interrogantes en torno al desarrollo tecnológico de la sociedad actual desde una relectura del pasado surgida de la imaginación. Desde este contexto, Félix J. Palma nos ofrece una novela en la que, al margen del mero interés narrativo, se reflexiona en torno a dos ideas que se entrecruzan en la historia una y otra vez: la literatura y el tiempo. Respecto a la primera, la novela se sirve de constantes elementos autorreferenciales con los que hacernos entender la narrativa en cuanto auténtico constructo manejado a voluntad por el autor. De igual modo, las metalepsis y los saltos narrativos adquieren casi un valor lúdico en el texto, dando lugar a más de una situación paradójica que lleva, en última instancia, a entender el valor metaliterario de la novela, independientemente de que por ella desfilen autores reconocibles por todos, destacando en particular la figura de H. G. Wells. Pero estos juegos con las instancias narrativas no tendrán valor tan solo en sí mismos, sino que servirán de conexión con el otro gran ámbito temático de la obra, es decir, la idea de tiempo. En este sentido, la obra propone entender el proceso de escritura-lectura en clave metafórica, en la medida en que la literatura nos enfrenta al vértigo de la elección -escribir esto o aquello, leer o no leer-, viendo así el proceso creativo en cuanto camino de senderos 
que se bifurcan, lo que nos lleva de frente a uno de los pilares de la narrativa steampunk: los universos paralelos. Una vez asentadas estas ideas en la novela, Palma apuesta por su última gran tesis: el cuestionamiento de la propia idea de tiempo. Así, la sucesión de guiños, confusiones e incongruencias, a partir de los viajes temporales, sumada a ciertas reflexiones de índole teórica sobre la consideración del tiempo en cuanto cuarta dimensión, parecen conducir al lector a la conclusión de que el devenir histórico es solo una construcción simbólica más, susceptible de reinterpretaciones culturales ante las cuales ya no es tan fácil responder a la pregunta "¿qué significa ahora?”.

En resumen, quizás sea hora ya de que nos acerquemos a la ciencia-ficción, y en particular al subgénero emergente -aunque de incierta evolución-del steampunk, desposeídos de los prejuicios que tradicionalmente nos han llevado a ver los géneros no realistas como mera literatura de evasión, vacía de contenido. Por el contrario, la elaboración de universos alternativos quizás posea un potencial para la reflexión teórica -como se ha visto a propósito de El mapa del tiempoque escapa a la narrativa de la cotidianidad. De ser así, absurdo sería entonces renunciar al valor especulativo de la literatura no mimética enturbiados por el prejuicio que otorga mayor valor estético al arte documental.

\section{Bibliografía}

AYALA, M. de los Á. (1998). "La obra narrativa de Enrique Gaspar: El Anacronópete (1887)" en Del Romanticismo al Realismo: Actas del I Coloquio de la Sociedad de Literatura Española del Siglo XX. (Eds. L. F. Díaz Larios y E. Miralles). Barcelona: Universitat de Barcelona.

BARADIT, J. (2008). Synco. Barcelona: Ediciones B.

BLAYLOCK, J. P. (1986). Homunculus. New York: Ace Books.

CONTE IMBERT, D. (2011). "El mundo de las ciudades oscuras, de Schuiten y Peeters: una topografía de la desubicación". Ángulo recto. Revista de estudios sobre la ciudad como espacio plural 3 (2): 247-277.

FERNÁNDEZ, L. (2011). "Llega por fin a España la novela "steampunk", $<\mathrm{http}$ ://www.siis.net/documentos/hemeroteca/111206_12.pdf>. (Acceso 10 Marzo 2017).

FUNDACIÓN TELEFÓNICA (2015). "Tesla Steampunk: viaje al retrofuturo" <http://www.fundaciontelefonica.com/2015/01/08/tesla-steampunk-2/>. (Acceso 14 Marzo 2017). 
GARCIA COSTA, J. (2013). "Steampunk": Utopismo e Neovitorianismo nos séculos XX e XXI. Lisboa: Universidade Nova de Lisboa.

GASPAR y RIMBAU, E. (1887). El Anacronópete. Barcelona: Daniel Cortezo y Ca GENETTE, G. (2004). Metalepsis. De la figura a la ficción. México: Fondo de Cultura Económica.

HESLES SÁNCHEZ, G. J. (2013). El viaje en el tiempo en la literatura de ciencia ficción española (Tesis doctoral). Universidad Complutense de Madrid. $<$ http://eprints.ucm.es/21401/1/T34464.pdf>. (Acceso 8 Noviembre 2017).

JETER, K. W. (1987). Infernal Devices. New York: St. Martin's Press.

LARAWAY, D. (2013). "Back to the future: Salvador Allende's Steampunk Chile". A Contracorriente. A Journal on Social History and Literature in Latin America 11 (1): 152-169.

MARTÍN RODRÍGUEZ, M. (2013). “"El retrofuturismo literario'. En torno a Steampunk: Antología retrofuturista". Hélice. Reflexiones críticas sobre ficción especulativa II (2): 64-72.

MATANGRANO, B. A. (2016). "O olhar contemporâneo na releitura do moderno: A lição de anatomia do temivel Dr. Louison". Estudos de Literatura Brasileira Contemporãnea 48: 247-280.

MAIOLINO HERSCHMANN, M. et al. (2013). "Steampunk e retrofuturismo: reflexos de inquietações sociotemporais contemporãneas". Comunicação, Mídia e Consumo 10 (28): 209-228.

MEIER, S. (2007). La segunda enciclopedia de Tlön. Valparaíso: Puerto de Escape. MONTESDEOCA, R. (2013). La máquina del Juicio Final. Salamanca: Dlorean Ediciones.

MOORE, A. y O'NEIL, K. (1999-2012). The League of Extraordinary Gentlemen. Burbank: DC Comics.

ONION, R. (2008). "Reclaiming the Machine: An Introductory Look at Steampunk in Everyday Practice". Neo-Victorian Studies 1 (1): 138-163.

ORTEGA, F. (2011). 1899: Cuando los tiempos chocan. Barcelona: Norma.

PALMA, F. J. (2009). El mapa del tiempo. Madrid: Alianza Editorial.

PALMA, F. J. (Coord.) (2012). Steampunk: antología retrofuturista. Madrid: Fábulas de Albión.

PALMA, F. J. (2014). "El mapa de los mapas" [Conferencia plenaria impartida en el Congreso Internacional "Figuraciones de lo Insólito en las Literaturas española e hispanoamericana", celebrado en la Universidad de León, 5-7 Noviembre 2014] <https://buleria.unileon.es/bitstream/handle/10612/4374/ F\%C3\%89LIX\%20J.\%20PALMA.\%20EL\%20MAPA\%20DE\%20LOS\%20 MAPAS.pdf?sequence=1>. (Acceso 10 Marzo 2017). 
PEGORARO, É. (2012a). "Os steampunks e a cultura da mídia: apropriações de uma proposta retrofuturista no cenário brasileiro". Mediaciones Sociales 11: 83-106.

PEGORARO, É. (2012b). "Steampunk: as transgressões temporais negociadas de uma cultura retrofuturista". Cuadernos de Comunicação 16 (2): 389-400.

PEGORARO, É. (2013). "Steampunk in Brazil: Visuality and Sociability in an Urban Retrofuturistic Culture". International Journal of Communication 7: 1852-1863.

POWERS, T. (1983). The Anubis Gates. New York: Ace Books.

RAMOS, J. (2013). Lendaria. Salamanca: Dlorean Ediciones.

REMESAR, J. (2013). El dirigible. Salamanca: Dlorean Ediciones.

ROJAS, A. (2011). La sombra de fuego. Barcelona: Ediciones B.

STERLING, B. (2009). "The user's guide to steampunk". Steampunk Magazine 5: 30-33.

USHER, S. (2011). "The Birth of Steampunk" $<$ http://www.lettersofnote. com/2011/03/birth-of-steampunk.html >. (Acceso 14 Marzo 2017).

VAQUERIZO, E. (2005). Danza de tinieblas. Barcelona: Ediciones Minotauro.

VILLANUEVA, D. (1984). "Narratario y lectores implícitos en la evolución formal de la novela picaresca" en Estudios en honor a Ricardo Gullón. (Eds. L. T. González del Valle y D. Villanueva). Lincoln: Society of Spanish and Spanish-American Studies.

WOMACK, M. y WOMACK, J. (Coords.) (2015). The Best of Spanish Steampunk. Madrid: Ediciones Nevsky. 